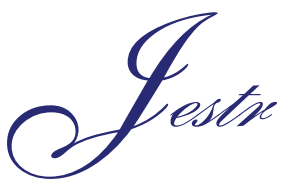

\title{
Exergy Analysis of Operating Lignite Fired Thermal Power Plant
}

\author{
T. Ganapathy ${ }^{*}, 1$, N. Alagumurthi ${ }^{2}$, R. P. Gakkhar ${ }^{1}$ and K. Murugesan ${ }^{1}$ \\ ${ }^{1}$ Department of Mechanical \& Industrial Engineering, Indian Institute of Technology, Roorkee, India. \\ ${ }^{2}$ Mechanical Engineering Department, Pondicherry Engineering College, Puducherry, India.
}

Received 24 December 2008; Accepted 14 October 2009

\begin{abstract}
The energy assessment must be made through the energy quantity as well as the quality. But the usual energy analysis evaluates the energy generally on its quantity only. However, the exergy analysis assesses the energy on quantity as well as the quality. The aim of the exergy analysis is to identify the magnitudes and the locations of real energy losses, in order to improve the existing systems, processes or components. The present paper deals with an exergy analysis performed on an operating 50MWe unit of lignite fired steam power plant at Thermal Power Station-I, Neyveli Lignite Corporation Limited, Neyveli, Tamil Nadu, India. The exergy losses occurred in the various subsystems of the plant and their components have been calculated using the mass, energy and exergy balance equations. The distribution of the exergy losses in several plant components during the real time plant running conditions has been assessed to locate the process irreversibility. The First law efficiency (energy efficiency) and the Second law efficiency (exergy efficiency) of the plant have also been calculated. The comparison between the energy losses and the exergy losses of the individual components of the plant shows that the maximum energy losses of $39 \%$ occur in the condenser, whereas the maximum exergy losses of $42.73 \%$ occur in the combustor. The real losses of energy which has a scope for the improvement are given as maximum exergy losses that occurred in the combustor.
\end{abstract}

Keywords: Energy, Exergy, Exergy efficiency, Energy losses, Exergy losses, Lignite, Thermal plant.

\section{Introduction}

The exergy method of analysis is based on the Second law of thermodynamics and the concept of irreversible production of entropy. The fundamentals of the exergy method were laid down by Carnot in 1824 and Clausius in 1865. The energy-related engineering systems are designed and their performance is evaluated primarily by using the energy balance deduced from the First law of thermodynamics. Engineers and scientists have been traditionally applying the First law of thermodynamics to calculate the enthalpy balances for more than a century to quantify the loss of efficiency in a process due to the loss of energy. However, in recent years the Second law analysis, herein after called the exergy analysis, of energy systems has more and more drawn the interest of energy engineers and scientific community. The exergy concept has gained considerable interest in the thermodynamic analysis of thermal processes and plant systems since it has been seen that the First law analysis has been insufficient from an energy performance stand point. The exergy method of analysis has been developed and has been used in Russia, Europe, Germany and Poland

* E-mail address: tganadme@iitr.ernet.in ISSN: 1791-2377 C 2009 Kavala Institute of Technology. All rights reserved. from the year 1960 [1-2].

Based on the Second law of thermodynamics, the exergy analysis represents the third step in the plant systems analysis, following the mass and the enthalpy balances. The aim of the exergy analysis is to identify the magnitudes and the locations of exergy losses, in order to improve the existing systems, processes or components, or to develop new processes or systems [3]. This analysis allows one to quantify the loss of efficiency in a process due to the loss in energy quality. It cannot apparently point out how the process can be enhanced. However it can specify where the process can be improved and therefore, it will signify what areas should be given consideration. The simple energy balance will not sometimes suffice to find out the system flaws. In such circumstances the exergy analysis is well thought-out to be significant to locate the systems imperfections. Recently a large number of studies based on exergy analysis have been carried out by many researchers all over the world in various system applications [4-11].

Horlock et al. [12] estimated the rational efficiencies of three modern fossil-fuel power plants using the exergy calculations. They analyzed the effect of water or steam injection on the rational efficiency of the plant. The relation between the irrevers- 
ibility in combustion and the loss of exergy due to mixing in the exhaust was also considered in their analysis. Rosen [13-15] has applied exergy analyses to a wide range of processes including the production of hydrogen and hydrogen-derived fuels, electrical and thermal power generation, thermal energy storage, and the energy utilization of countries. He also examined the several significant implications of exergy analyses in the fields of environmental impact and economics.

Jin et al. [16] analyzed two operating advanced power plants using a methodology of graphical exergy analysis. They pointed out the inefficient segments in the combined cycle plant. They stated that the inferior performance of the combined cycle plant are due to the higher exergy loss caused by mixing in the combustor, the higher exergy waste from the heat recovery steam generator and the higher exergy loss in the bottoming cycle. Moran et al. [17] provided a brief survey of exergy principles and analyses along with emphasis on areas of application. They concluded that the exergy balance can be used to determine the location, type, and true magnitude of the waste of energy resources, and thus can play an important part in developing strategies for more effective fuel use. Salih Dincer calculated exergies of the physical and the chemically reacting processes using the exergy analysis [18]. He also reported the calculation of exergy efficiency of a petroleum refinery including only separation, heating and cooling processes. In the present work, an exergy analysis has been performed on $50 \mathrm{MW}_{\mathrm{e}}$ power generation capacity, unit $\mathrm{V}$ of thermal power station-I of Neyveli Lignite Corporation Limited, Neyveli to find out the exergy losses in various components of the plant. The exergy efficiency of the plant and its individual components has also been evaluated and the plant's real losses of energy are computed.

\section{Description of the plant}

A schematic diagram of the plant with its various significant components, considered for the present study is shown in Fig. 1. The continuous supply of de-mineralized water is ensured to the condenser hot well for the normal running of the plant at $50 \mathrm{MW}_{\mathrm{e}}$ load condition. The condensate extraction pump (CEP) feeds the feed water to the ejector $(\mathrm{Ejec})$ from the hot well. After the ejector exit, the feed water passes through the gland steam cooler $\left(\mathrm{C}_{\mathrm{GS}}\right)$, and the low pressure heaters $\left(\mathrm{H}_{\mathrm{LP}}\right)$. From the outlet of the last low pressure heater $\left(\mathrm{H}_{\mathrm{LP5}}\right)$ the condensate enters into the de-aerator shell which is situated at $42 \mathrm{~m}$ height from the ground level. Two feed pumps are provided to supply the condensate from the de-aerator to the high pressure heaters $\left(\mathrm{H}_{\mathrm{HP}}\right)$. Then the condensate passes through the bottom economizer (B. Econ), the boiler condenser (B. Con), the top economizer (T. Econ) and finally it enters into the boiler drum. There is a continuous circulation of water between the drum and the water walls and a part of the feed water is converted into steam.

The steam is separated in the boiler drum and supplied to the super heater section and the boiler condenser section. The super heated steam produced in the super heater then enters into the turbine through the turbine stop valve. After expansion in the turbine the exhaust steam is condensed in the condenser and is used for the closed cycle as shown in Fig. 1. For regenerative heating of the condensate, the steam extracted from the various points is also shown in the schematic diagram (Fig. 1).

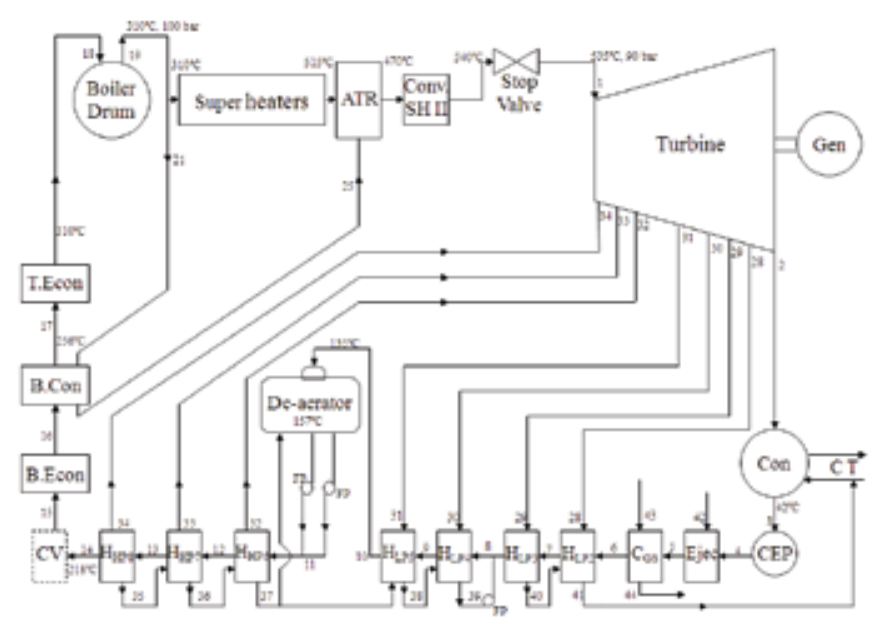

Figure 1. Schematic diagram of the plant at NLC Neyveli

\section{Methodology}

The several components of the plant are grouped into three subsystems namely, boiler subsystem, steam cycle or thermal cycle subsystem and cooling tower subsystem as shown in Fig. 2. The components of the boiler subsystem are the combustor and the heat exchangers. Steam cycle subsystem includes the components such as, the turbine, the condenser, the feed water heaters and the pumps. The circulating water pump, the cooling tower and the fans constitute the cooling tower subsystem. The imaginary boundaries enveloping the components of the boiler subsystem, the steam cycle subsystem, the cooling tower subsystem and the total plant are denoted respectively by the control surfaces " $\mathrm{S}_{1}$ ", " $\mathrm{S}_{2}$ ", " $\mathrm{S}_{3}$ ", and "S" as shown in Fig. 2. The mass, energy and exergy flow across the control surface have been used for the exergy analysis calculations of the individual subsystem.

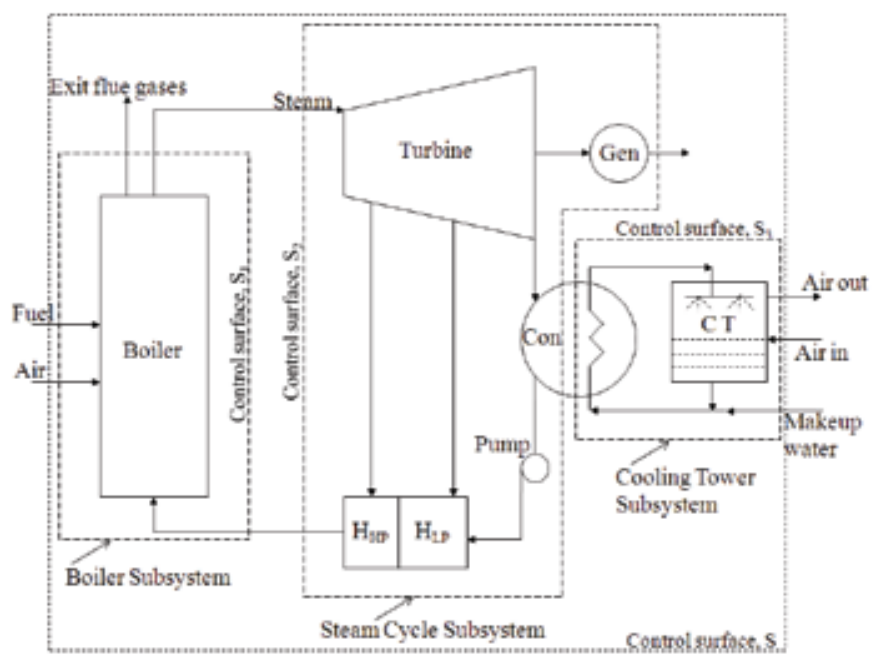

Figure 2. Subsystems of the plant 
The exergy analysis has been carried out for each component in the subsystems, to evaluate the exergy losses in the individual component and then the analysis is performed on the overall individual subsystems, to find out the exergy losses in each susbsystem. Finally the exergy analysis for the overall plant has been carried out and the total plant exergy losses have been computed. The energy and the exergy losses of the components of each system have been determined using their mass, energy and exergy balance equations. The exergy destructions for each components and subsystems are then compared and presented. The energy and exergy efficiencies have also been computed for the individual components as well as for the overall plant.

\section{Exergy analysis}

The exergy analysis is the combination of the First and Second laws of thermodynamics. In this analysis the heat does not have the same value as the work, and the exergy losses represent the real losses of work. When analyzing novel and complex thermal systems, experience needs to be supplemented by more rigorous quantitative analytical tools. Exergy analysis provides those tools and it helps in locating weak spots in a process. This analysis provides a quantitative measure of the quality of the energy in terms of its ability to perform work and leads to a more rational use of energy. In general, the specific exergy denoted by " $\varepsilon$ " is calculated using the equation as given below.

$\varepsilon=\varepsilon_{\mathrm{k} . \mathrm{e}}+\varepsilon_{\mathrm{p} . \mathrm{e}}+\varepsilon_{\mathrm{ph}}+\varepsilon_{\mathrm{ch}}$

Where, $\varepsilon_{\mathrm{k} . \mathrm{e}}$ and $\varepsilon_{\mathrm{p} . \mathrm{e}}$ are exergy due to velocity (or) kinetic energy and exergy due to potential energy respectively. $\varepsilon_{\mathrm{ph}}$ is physical exergy i.e. exergy due to temperature difference and pressure difference with respect to the reference point and $\varepsilon_{\mathrm{ch}}$ is chemical exergy (i.e due to reactions). In the present analysis, it is assumed that the exergy due to kinetic energy and potential energy are negligible. Also, for the exergy calculations, the atmospheric temperature and pressure are taken respectively as $30^{\circ} \mathrm{C}$ and 101.325 $\mathrm{kPa}$.

\subsection{Boiler subsystem}

The energy losses $(\dot{Q})$ of the subsystem components are determined using the energy balances of the First law and similarly the exergy losses $(\dot{I})$ are calculated from the exergy balance equations of the Second law. Then using the energy losses the energy efficiency (the First law efficiency) is calculated and the exergy efficiency (the Second law efficiency) is determined using the exergy losses.

\subsubsection{Combustor}

For a combustor as shown in Fig. 3 the mass, energy and exergy balances are

$$
\dot{m}_{f}+\dot{m}_{a}=\dot{m}_{g}
$$

$$
\begin{aligned}
& \dot{m}_{f}\left(h_{f}-h_{g}\right)+\dot{m}_{a}\left(h_{a}-h_{g}\right)=\dot{Q}_{C} \\
& \dot{m}_{f}\left(\varepsilon_{f}-\varepsilon_{g}\right)+\dot{m}_{a}\left(\varepsilon_{a}-\varepsilon_{g}\right)-\dot{E}_{Q_{C}}=\dot{I}_{C}
\end{aligned}
$$

where the fuel (lignite) enters the combustor at ambient temperature and pressure and heat energy losses occurs at $70^{\circ} \mathrm{C}$.

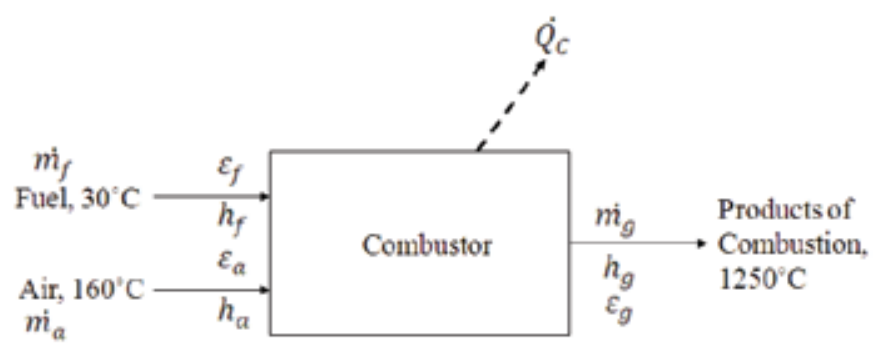

Figure 3. Energy and exergy balances for combustor

\subsubsection{Super heaters}

The super heaters of the plant include roof super heaters, screen super heaters and convective super heaters. The energy and exergy balances of the super heaters are shown in the block diagram (Fig. 4). The equations employed for the analysis of the super heaters are

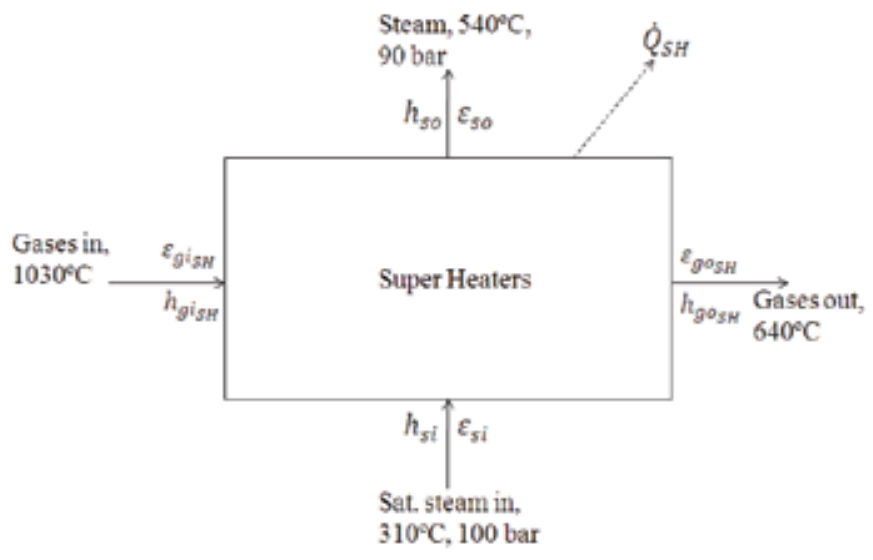

Figure 4. Energy and exergy balances for super heaters

Mass balance:

For gas side:

$\dot{m}_{g i_{S H}}=\dot{m}_{g o_{S H}}=\dot{m}_{g}$

For steam side:

$\dot{m}_{s i}=\dot{m}_{s o}=\dot{m}_{s}$

Energy balance:

$\dot{m}_{g}\left(h_{g i_{S H}}-h_{g o_{S H}}\right)+\dot{m}_{s}\left(h_{s i}-h_{s o}\right)=\dot{Q}_{S H}$ 
Exergy balance:

$\dot{m}_{g}\left(\varepsilon_{g i_{S H}}-\varepsilon_{g o_{S H}}\right)+\dot{m}_{s}\left(\varepsilon_{s i}-\varepsilon_{s o}\right)-\dot{E}_{Q_{S H}}=\dot{I}_{S H}$

where the heat losses from the super heaters occur at $65^{\circ} \mathrm{C}$.

\subsubsection{Heat recovery system}

The heat recovery system consists of the two economizers and three air pre-heaters as shown in Fig. 5. The following equations are obtained from the mass, energy and exergy balances for the analysis of the heat recovery system.

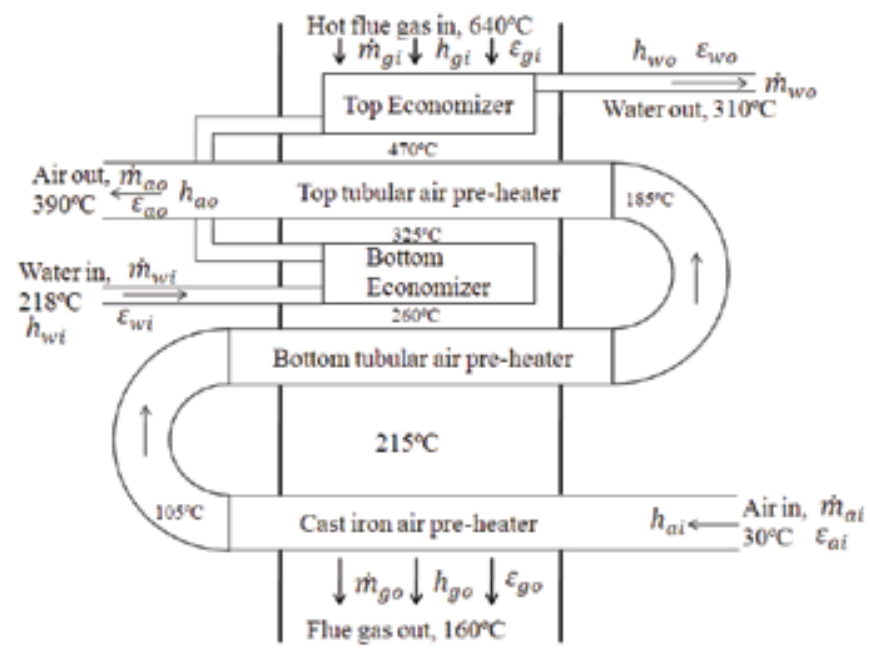

Figure 5. Heat recovery system

For air:

$\dot{m}_{a i}=\dot{m}_{a o}=\dot{m}_{a}$

For water:

$\dot{m}_{w i}=\dot{m}_{w o}=\dot{m}_{w}$

For hot gases:

$\dot{m}_{g i}=\dot{m}_{g o}=\dot{m}_{g}$

$\dot{m}_{g}\left(h_{g i}-h_{g o}\right)+\dot{m}_{w}\left(h_{w i}-h_{w o}\right)+$

$+\dot{m}_{a}\left(h_{a i}-h_{a o}\right)=\dot{Q}_{H E}$

$\dot{m}_{g}\left(\varepsilon_{g i}-\varepsilon_{g o}\right)+\dot{m}_{w}\left(\varepsilon_{w i}-\varepsilon_{w o}\right)+$

$+\dot{m}_{a}\left(\varepsilon_{a i}-\varepsilon_{a o}\right)-\dot{E}_{Q_{H E}}=\dot{I}_{H E}$

where the heat energy losses from the system occur at $40^{\circ} \mathrm{C}$.

\subsubsection{Overall boiler subsystem}

The overall boiler subsystem of the plant is indicated by the con- trol surface " $\mathrm{S}_{1}$ " as shown in Fig. 2. The overall boiler losses are calculated using the indirect method of energy losses [19]. The energy efficiency of the boiler is then calculated from these losses. The exergy losses and the exergy efficiency are determined using the equations given below.

$$
\begin{aligned}
& \dot{m}_{f}\left(\varepsilon_{f}-\varepsilon_{g}\right)+\dot{m}_{a}\left(\varepsilon_{a}-\varepsilon_{g}\right)+ \\
& +\dot{m}_{s}\left(\varepsilon_{w}-\varepsilon_{s}\right)-\dot{E}_{Q_{B}}=\dot{I}_{B} \\
& \Psi_{B}=\left[m_{s}\left(\varepsilon_{s}-\varepsilon_{w}\right) / m_{f} \varepsilon_{f}\right] x 100
\end{aligned}
$$

\subsection{Steam cycle subsystem}

This subsystem includes five important components namely, steam turbine, condenser, feed water heaters, main condensate pump and feed pumps. The mass, enthalpy and exergy balances of the subsystem components are detailed in this section. The equations of energy balances for each component as given below are used to find out the energy losses whereas the exergy destructions are found out from the exergy balances.

\subsubsection{Steam turbine}

The various state points (28 to 34 ) at which the steam is extracted for regenerative purposes are indicated in Fig. 1. The mass, energy and exergy balances for the steam turbine are

$\dot{m}_{1}=\dot{m}_{2}+\sum_{x=28}^{34} \dot{m}_{x}$

$\dot{m}_{1} h_{1}-\dot{m}_{2} h_{2}-\sum_{x=28}^{34} \dot{m}_{x} h_{x}-\dot{W}_{T}=\dot{Q}_{T}$

$\dot{m}_{1} \varepsilon_{1}-\dot{m}_{2} \varepsilon_{2}-\sum_{x=28}^{34} \dot{m}_{x} \varepsilon_{x}-\dot{W}_{T}-\dot{E}_{Q_{T}}=\dot{I}_{T}$

where the dryness fraction of steam at the turbine exit is denoted by $\mathrm{x}_{2}=0.88$ and the heat loss occurs from the turbine surface at a temperature of $38^{\circ} \mathrm{C}$.

\subsubsection{Condenser}

The exhaust steam from the turbine enters into the condenser at $46^{\circ} \mathrm{C}$ and leaves it at $42^{\circ} \mathrm{C}$. The mass, energy and exergy balances of the condenser (Fig. 1) are given by

$$
\dot{m}_{2}=\dot{m}_{3}
$$

$\dot{m}_{2}\left(h_{2}-h_{3}\right)=\dot{Q}_{C o n}$ 


$$
\dot{m}_{2}\left(\varepsilon_{2}-\varepsilon_{3}\right)-\dot{E}_{Q_{C o n}}=\dot{I}_{C o n}
$$

where the heat rejection from the condenser takes place at $38^{\circ} \mathrm{C}$.

\subsubsection{Feed water heaters}

There are four low pressure heaters and three high pressure heaters used for regeneration in the plant. The mass, energy and exergy balances for the analysis of the feed water heaters system as shown in Fig. 6 are as follows:

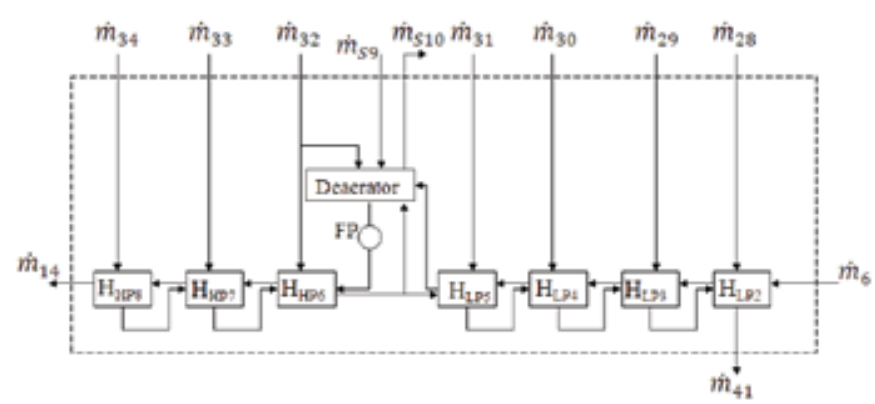

Figure 6. Feed water heaters

$\dot{m}_{6}+\sum_{x=28}^{34} \dot{m}_{x}+\dot{m}_{S 9}=\dot{m}_{14}+\dot{m}_{41}+\dot{m}_{S 10}$

$\dot{m}_{6} h_{6}+\sum_{x=28}^{34} \dot{m}_{x} h_{x}+\dot{m}_{S 9} h_{S 9}-\dot{m}_{14} h_{14}-$

$-\dot{m}_{41} h_{41}-\dot{m}_{S 10} h_{S 10}=\dot{Q}_{F W H}$

$\dot{m}_{6} \varepsilon_{6}+\sum_{x=28}^{34} \dot{m}_{x} \varepsilon_{x}+\dot{m}_{S 9} \varepsilon_{S 9}-\dot{m}_{14} \varepsilon_{14}-$

$-\dot{m}_{41} \varepsilon_{41}-\dot{m}_{S 10} \varepsilon_{S 10}-\dot{E}_{Q_{F W H}}=\dot{I}_{F W H}$

where the heat losses from the system occur at an average temperature of $30^{\circ} \mathrm{C}$. The energy and exergy losses in ejector, gland steam cooler and de-aerator are neglected because of negligible magnitude. It can be noted that the exergy loss due to the heat loss from the feed water heaters (at ambient temperature) is zero.

\subsubsection{Condensate extraction pump}

The following equations represent the mass, energy and exergy balances for the condensate extraction pump as shown in Fig. 1.

$$
\dot{m}_{3}=\dot{m}_{4}
$$

$\dot{m}_{3}\left(h_{3}-h_{4}\right)+\dot{W}_{C E P}=\dot{Q}_{C E P}$

$\dot{m}_{3}\left(\varepsilon_{3}-\varepsilon_{4}\right)+\dot{W}_{C E P}=\dot{I}_{C E P}$ where the heat losses from the condensate extraction pump (CEP) occur at ambient temperature. It can be noted that the exergy loss due to the heat loss from the pumps (at ambient temperature) is zero.

\subsubsection{Feed pumps}

The mass, energy and exergy balances of the feed pumps give the following equations to find out the energy and exergy losses. It can be noted that the exergy loss due to the heat loss from the pumps (at ambient temperature) is zero.

$\dot{m}_{f p i}=\dot{m}_{f p o}$

$\dot{m}_{f p i}\left(h_{f p i}-h_{f p o}\right)+\dot{W}_{F P}=\dot{Q}_{F P}$

$\dot{m}_{f p i}\left(\varepsilon_{f p i}-\varepsilon_{f p o}\right)+\dot{W}_{F P}=\dot{I}_{F P}$

\subsubsection{Overall steam cycle subsystem}

The overall steam cycle subsystem of the plant is indicated by the control surface " $\mathrm{S}_{2}$ " in Fig. 2. The energy and exergy losses are determined from the mass, energy and exergy balance equations given below. The First law efficiency and the Second law efficiency of the subsystem are calculated from these losses.

$$
\begin{aligned}
& \dot{m}_{1}=\dot{m}_{14} \\
& \dot{m}_{1}\left(h_{1}-h_{14}\right)-\dot{Q}_{C o n}-\dot{W}_{T}=\dot{Q}_{S C} \\
& \dot{m}_{1}\left(\varepsilon_{1}-\varepsilon_{14}\right)-\dot{E}_{Q_{C o n}}-\dot{W}_{T}-\dot{E}_{Q_{S C}}=\dot{I}_{S C}
\end{aligned}
$$

\subsection{Cooling tower subsystem}

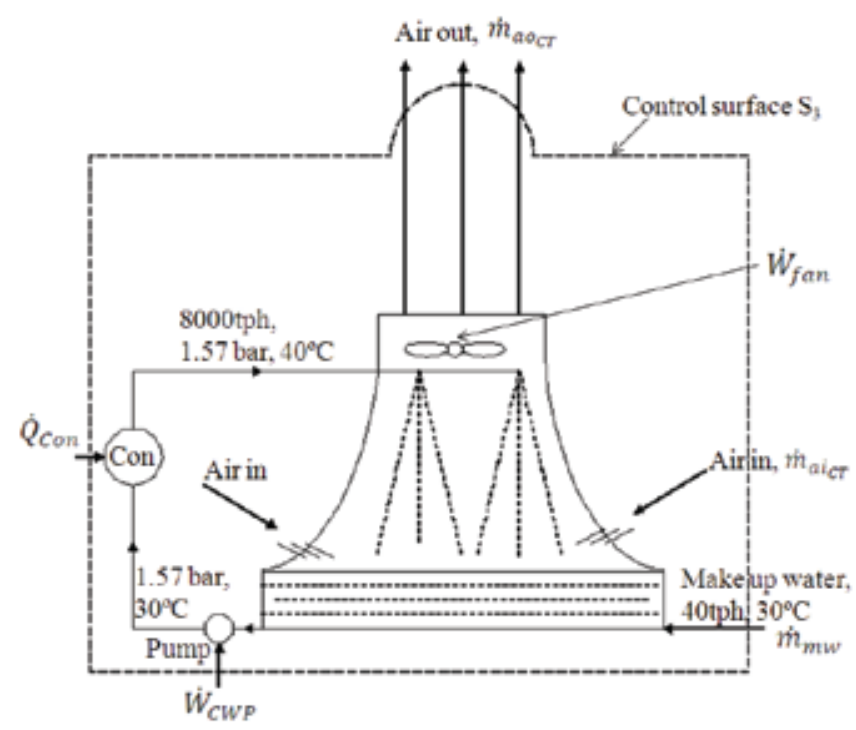

Figure 7. Cooling tower subsystem 
The schematic diagram of the cooling tower subsystem for the 50MWe plant is shown in Fig. 7. Since the heat losses and exergy destructions at each component of the subsystem are very small, they were not included in the analysis. The energy loss of the overall cooling tower subsystem has been calculated as $3.63 \%$. The energy and exergy losses are found out using the following equation.

For air:

$\dot{m}_{a i_{C T}}=\dot{m}_{a o_{C T}}=\dot{m}_{a_{C T}}$

For water:

$\dot{m}_{m w}=\dot{m}_{a_{C T}}\left(\omega_{a o_{C T}}-\omega_{a i_{C T}}\right)$

$\dot{m}_{a_{C T}}\left[\left(\omega_{a o_{C T}}-\omega_{a i_{C T}}\right) h_{m w}+\left(h_{a i_{C T}}-h_{a o_{C T}}\right)\right]+$

$+\dot{Q}_{C o n}+\dot{W}_{C W P}+\dot{W}_{f a n}=\dot{Q}_{C T}$

$$
\begin{aligned}
& \dot{m}_{a_{C T}}\left[\left(\omega_{a o_{C T}}-\omega_{a i_{C T}}\right) \varepsilon_{m w}+\left(\varepsilon_{a i_{C T}}-\varepsilon_{a o_{C T}}\right)\right]+ \\
& +\dot{E}_{Q_{C o n}}+\dot{W}_{C W P}+\dot{W}_{f a n}-\dot{E}_{Q_{C T}}=\dot{I}_{C T}
\end{aligned}
$$

In this analysis, the control surface " $\mathrm{S}_{3}$ " includes the region of mixing between the hot water, humid air, and the ambient air. The makeup water is assumed to enter the system at ambient temperature and pressure.

\subsection{Exergy analysis of the overall plant}

The exergy analysis is carried out for the overall $50 \mathrm{MW}_{\mathrm{e}}$ plant by considering the energy and exergy flows across the control surface "S" (Fig. 2). The energy balance and exergy balances are given by the equations $38 \& 39$ respectively. From these equations the total energy losses $\left(Q_{\text {Plant }}\right)$ and the total exergy losses $\left(I_{\text {Plant }}\right)$ of the plant have been deduced. The First law and the Second law efficiencies of the plant have then been evaluated [16].

$$
\begin{aligned}
& \dot{m}_{f} h_{f}+\dot{m}_{a} h_{a}+\dot{m}_{a_{C T}}\left[\left(\omega_{a o_{C T}}-\omega_{a i_{C T}}\right) h_{m w}+\right. \\
& \left.+\left(h_{a i_{C T}}-h_{a o_{C T}}\right)\right]-\dot{m}_{g} h_{g}-\dot{W}_{n e t}=\dot{Q}_{\text {Plant }} \\
& \dot{m}_{f}\left(\varepsilon_{f}-\varepsilon_{g}\right)+\dot{m}_{a}\left(\varepsilon_{a}-\varepsilon_{g}\right)+\dot{m}_{a_{C T}}\left[\left(\omega_{a o_{C T}}-\right.\right. \\
& \left.\left.-\omega_{a i_{C T}}\right) \varepsilon_{m w}++\left(\varepsilon_{a i_{C T}}-\varepsilon_{a o_{C T}}\right)\right]- \\
& -\dot{W}_{n e t}-\dot{E}_{Q_{\text {Plant }}}=\dot{I}_{\text {Plant }}
\end{aligned}
$$

\section{Discussions}

The operating data of the plant components such as, combustor, super heaters, top economizer, bottom economizer, top tubular air pre-heater, bottom tubular air pre-heater, cast iron air pre-heat- er, steam turbine, condenser, feed water heaters, main condensate pump, feed water pump, cooling water, makeup water, air, induced draft fan, and circulating water pump of the unit $\mathrm{V}$ of Thermal Power Station-I, Neyveli Lignite Corporation Limited, Neyveli at $50 \mathrm{MW}_{\mathrm{e}}$ grid load, collected by one of the authors [19] and have been used for the present exergy analysis to calculate the enthalpies and exergies at different state points. The energy and the exergy losses of these components have been determined using the equations given in the previous section.

From the energy analysis, the overall plant energy losses are calculated as $73 \%$. The comparison of energy losses between different components is given in Fig. 8. It can be observed that the maximum energy loss (39\%) occurred in the condenser. This is due to the reason that heat energy expulsion from the condenser is 83.308 MW. Thus the First law analysis (energy analysis) diverts our attention towards the condenser for the plant performance improvement. Since the condenser temperature of $42^{\circ} \mathrm{C}$ and water inlet temperature of $30^{\circ} \mathrm{C}$ were used in the analysis, the maximum possible power production from the energy expelled in the condenser would be only $3.16 \mathrm{MW}$, thereby reducing the total plant energy losses to $70 \%$ at the most. Approximately half of the total plant energy losses occur in the condenser only and these losses are practically useless for the generation of electric power. Thus the analysis of the plant based only on the First law principles may mislead to the point that the chances of improving the electric power output of the plant is greater in the condenser by means of reducing its huge energy losses, which is almost impracticable. Hence the First law analysis (energy analysis) cannot be used to pinpoint prospective areas for improving the efficiency of the electric power generation. However, the Second law analysis serves to identify the true power generation inefficiencies occurring throughout the power station.

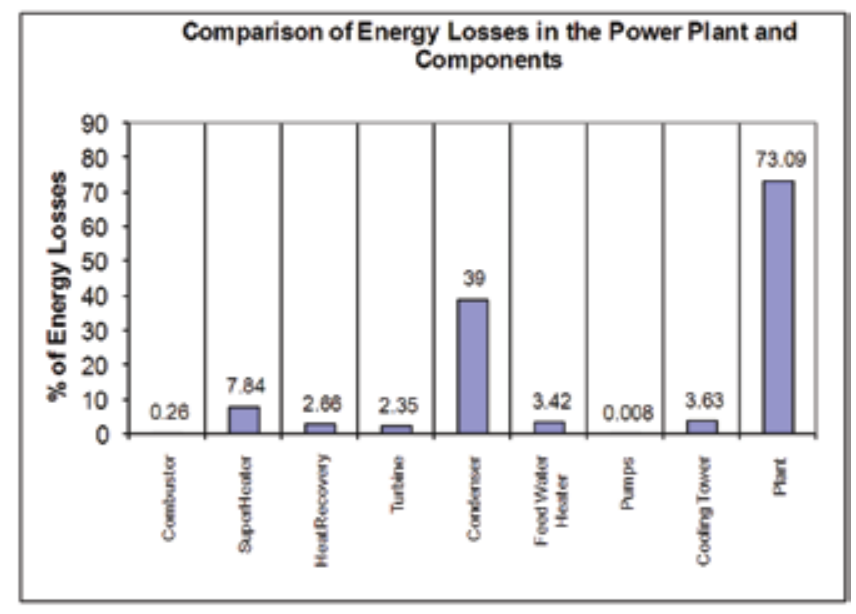

Figure 8. Comparison of energy losses in the plant and components

The comparison of exergy losses between the different subsystems of the plant are shown in Fig. 9. It can be noted that the maximum exergy loss occurs in the Boiler Subsystem (57.35\%). Also out of this, $42.73 \%$ losses took place in the combustor only. That is approximately $60 \%$ of the total plant exergy losses occur in the combustor. This may be due to the irreversibility of the combustion process in the combustor. The percentage of exergy 
losses for the plant components are compared and shown in Fig. 10. The total plant exergy destruction is calculated as $73 \%$.

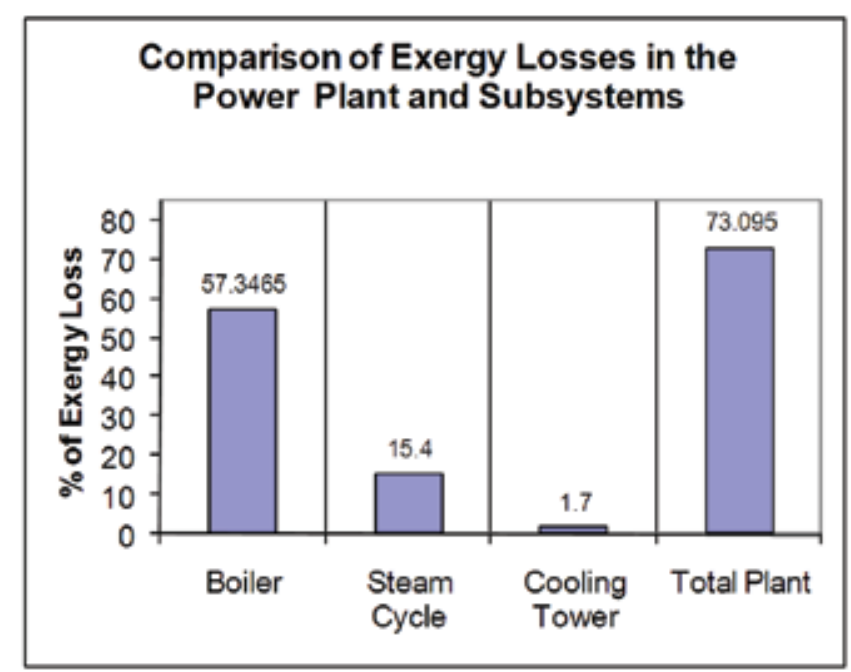

Figure 9. Exergy losses in the plant and subsystems

The Second law efficiency (the exergy efficiency) of different components is also calculated and their comparison is depicted in Fig. 11. It can be noted that the exergy efficiency of the turbine, the feed water heaters and the heat exchangers are $81.2 \%, 81.2 \%$, and $72.1 \%$ respectively. The exergy efficiency of the boiler and the condenser are calculated as $41.72 \%$ and $28.75 \%$ respectively. The overall plant exergy efficiency is $27 \%$. Thus the exergy analysis of the plant pinpoints that the prospective improvement in the combustor can improve the overall plant efficiency.

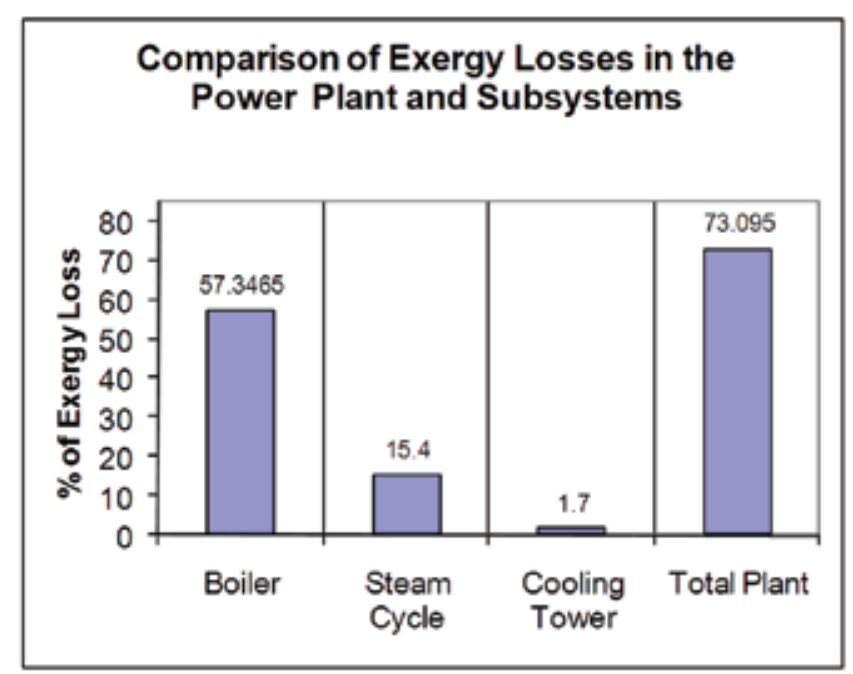

Figure 10. Exergy losses in the components of the plant

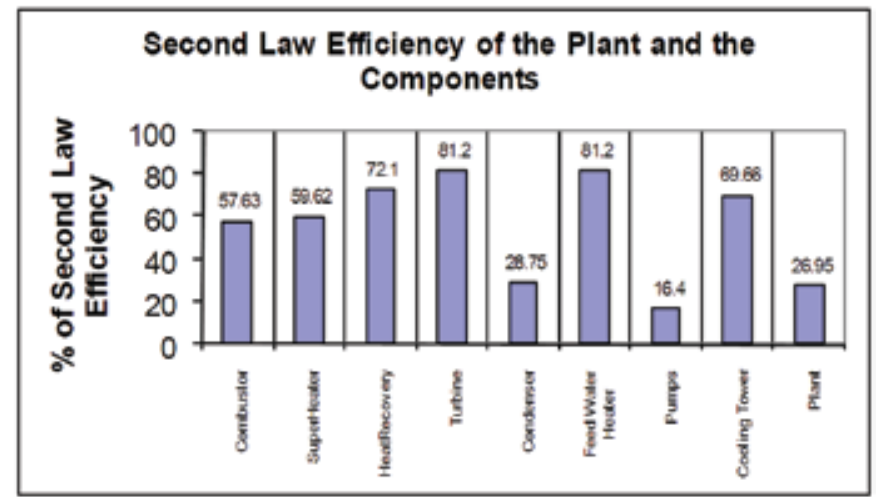

Figure 11. Second law efficiency of the plant and components

\section{Conclusions}

An exergy analysis was performed on an operating unit $\mathrm{V}$ of Thermal power station-I, at Neyveli Lignite Corporation Limited, at $50 \mathrm{MW}_{\mathrm{e}}$ output and the energy losses and the exergy destructions of the steam power plant components have been calculated. Exergy analysis results show that over $57 \%$ of exergy losses take place within the boiler system. Out of this, $42.7 \%$ of exergy loss occurs in the combustor only. This may be due to the irreversibility inherent in the combustion process, heat loss, incomplete combustion and exhaust losses. This study pinpoints that the combustor requires necessary modification to reduce its exergy destructions thereby the plant performance can be improved. The exergy efficiency of the plant is $27 \%$. But the results of energy analysis show that the major energy losses occurred in the condenser (39\%). However, these energy losses in the condenser cannot be practically utilized for the improvement of the power output of the plant. The first law efficiency of the plant is $27 \%$. Hence the exergy analysis locates the system or component where-in the necessary attention has to be paid to improve the performance of the plant.

\section{Acknowledgements}

The authors wish to thank Neyveli Lignite Corporation Limited, Neyveli, Tamil Nadu, India, for granting permission to carry out this work at Thermal Power Station-I. The valuable suggestions of Er. M. Seran, Deputy Superintendent, Neyveli Lignite Corporation Limited, is gratefully acknowledged.

\section{References}

1. J.E. Ahern, The Exergy Method of Energy Systems Analysis, Wiley, New York, 1980.

2. T.J. Kotas, The Exergy Method of Thermal Plant Analysis, Butterworths, London, U.K, 1985.

3. T. Tekin and M. Bayramoglu, Exergy Analysis of the Sugar Production Process from Sugar Beets, Int. J. of Energy Research, 22, $591-601$, 1998.
4. M.A. Habib, S.A.M. Said and Al-bagawi, Thermodynamic Analysis of the Ghazian Power Plant, Energy, 20 (11), 1121 - 1130, 1995.

5. W.R. Dunbar, S.C. Moody and N. Lior, Exergy Analysis of an Operating Boiling-Water-Reactor Nuclear Power Station, Energy Conversion \& Management, 36 (3), 149 - 159, 1995.

6. E.A. Khodak, G.A Romakhova, Thermodynamic Analysis of Air-Cooled Gas Turbine Plants, J. of Engg. for Gas Turbines \& Power, Vol. 123, 265 
-270, April 2001.

7. M.A. Smith, P.C. Few, Second law analysis of an experimental domestic scale co-generation plant incorporating a hear pump, Applied Thermal Engineering, 21, 93 - 110, 2001.

8. G.P. Hammond and A.J. Stapleton, Exergy analysis of the United Kingdom energy system, Proc. Instn. Mech Engrs. Vol. 215, Part A, pp 141 $-162,2001$.

9. Y-C Huang, C-I Hung and C-K Chen, Exergy analysis for a combined system of steam- injected gas turbine cogeneration and multiple-effect evaporation, Proc. Instn. Mech Engrs. Vol. 214, Part A, pp.61 - 73, 2000

10. Richard A. Gaggioli and William J. Wepfer, Second Law Analysis of Building Systems, Energy convers. \& Mgmt., Vol. 21, pp 65 - 75, 1981.

11. Unal Camdali, Murat Tunc, Feridun Dikec, A thermodynamic analysis of a steel production step carried out in the ladle furnace, Applied Thermal Engineering, 21, 643-655, 2001.

12. J.H. Horlock, J.B. Young, G. Manfrida, Exergy Analysis of Modern Fossil-Fuel Power Plants, J. of Engg. for Gas Turbines and Power, Vol. 122, $1-7$, Jan. 2000.

\section{Nomenclature}

E - exergy (kJ)

$\varepsilon \quad-$ specific Exergy $(\mathrm{kJ} / \mathrm{kg})$

I - exergy loss $(\mathrm{kJ})$

$h \quad$ - specific enthalpy $(\mathrm{kJ} / \mathrm{kg})$

$m$ - mass flow $(\mathrm{kg})$

$Q \quad$ - heat loss or thermal energy loss (kJ)

$W \quad$ - work $(\mathrm{kJ})$

$\mathrm{MW}_{\mathrm{e}}$ - Mega Watts electricity

$\Psi \quad$ - exergy efficiency or second law efficiency (\%)

$\omega \quad$ - specific humidity ( $\mathrm{kg}$ of water vapor / $\mathrm{kg}$ of dry air)

WBT - wet bulb temperature

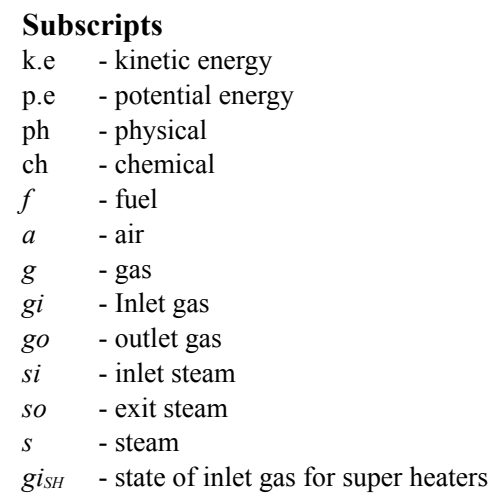

13. M.A. Rosen, Second-Law Analysis: Approaches and Implications, Int. J. of Energy Research, 23, 415 - 429, 1999.

14. M.A. Rosen, Exergy Methods for Assessing and Comparing Thermal Storage Systems, Int. J. of Energy Research, 27(4), 415 - 430, 2003.

15. M.A. Rosen, Assessing Energy Technologies and Environmental Impacts with the Principles of Thermodynamics, Applied Energy, 72, 427 - 441, 2002.

16. H. Jin, M. Ishida, M. Kobayashi, M. Nunokawa, Exergy Evaluation of Two Current Advanced Power Plants: Supercritical Steam Turbine and Combined Cycle, Trans. of ASME, Vol. 119, pp 250 - 256, Dec. 1997.

17. M.J. Moran and E. Scuibba, Exergy Analysis: Principles and Practice, J. of Engg. for Gas Turbines and Power, Vol. 116, 285 - 290, April 1994.

18. Salih Dincer, Available Energy Analysis, Energy Convers. Mgmt. Vol. 25, No.3, 309 - 313, 1985.

19. T. Ganapathy, Exergy analysis of coal fired thermal power plant (NLC, Neyveli), Major Project Report, M. Tech. Thesis, Pondicherry University, Pondicherry, Jan.2002.

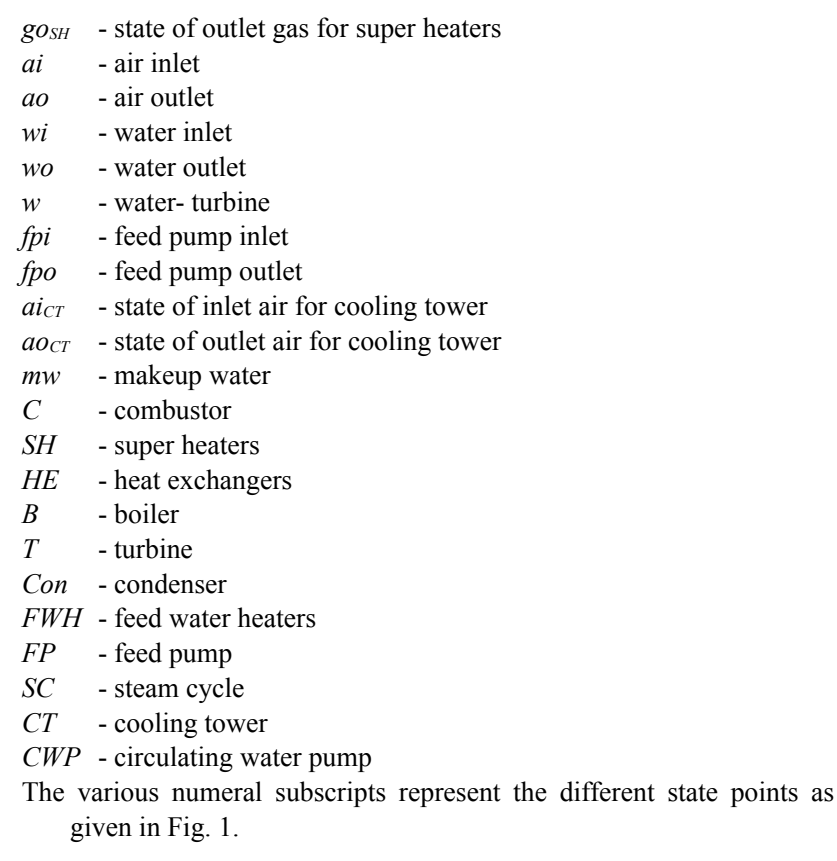

\section{Superscripts}

- quantity per unit time 